\title{
Translation into Brazilian Portuguese and validation of the "Quantitative Global Scarring Grading System for Post-acne Scarring" *
}

\author{
Thais Hofmann Cachafeiro ${ }^{1}$ \\ Gabriela Maldonado ${ }^{1}$
}

\author{
Gabriela Fortes Escobar \\ Tania Ferreira Cestari ${ }^{1}$
}

\begin{abstract}
The "Quantitative Global Scarring Grading System for Postacne Scarring" was developed in English for acne scar grading, based on the number and severity of each type of scar. The aims of this study were to translate this scale into Brazilian Portuguese and verify its reliability and validity. The study followed five steps: Translation, Expert Panel, Back Translation, Approval of authors and Validation. The translated scale showed high internal consistency and high test-retest reliability, confirming its reproducibility. Therefore, it has been validated for our population and can be recommended as a reliable instrument to assess acne scarring.
\end{abstract}

Keywords: Acne vulgaris; Cicatrix; Scales

Acne is a multifactorial inflammatory disease of the pilosebaceous follicles, affecting up to $80 \%$ of teenagers and $20 \%$ of adults., ${ }^{1,2}$ Scarring can occur early in acne development and may affect up to $95 \%$ of patients with this disease. ${ }^{2,3,4}$ All types of acne, from papulopustular through nodulocystic, can cause nonaesthetic and persistent scarring. ${ }^{3,5}$ Acne scars impair quality of life and have been described as a risk factor for suicide. ${ }^{5,6}$ Furthermore, they have been linked to poor self-esteem, depression, anxiety and lowered academic performance. . $^{25,6,7}$

Several methods for evaluating and grading active acne exist and are used frequently, allowing assessment of benefits of treatment. ${ }^{8}$ Similarly, it is necessary to grade post-acne scarring so as to select the most appropriate procedures for each lesion, increasing the chance of success. ${ }^{2}$ In addition, it allows comparisons to be made before and after treatments. ${ }^{2,9}$ Multiple acne scar grading classification systems, of varying complexities, have been proposed. ${ }^{2}$ In 2006, Goodman GF and Baron JA ${ }^{9}$ devel- oped a scale of global severity for acne scarring, known as the Quantitative Global Scarring Grading System for Post-acne Scarring. It relies on a scar count by type, calculating a score according to the number and severity of each type. ${ }^{9}$ The instrument grading limits are between $0-84$ points and it seems to be an accurate and reproducible tool. ${ }^{9}$

Various forms of evaluation of treatment results for acne scarring are in use, including: comparative photographs, patient clinical satisfaction and subjective physician clinical assessment. These different criteria contribute to the heterogeneity of acne scarring treatment results and hinder comparisons between different management options. Therefore, it is of the utmost importance that a more objective and widely used tool be applied. At present, there is no global quantitative grading system for assessing post-acne scarring validated in Brazilian Portuguese.

The aim of this study was to translate the Quantitative Global Scarring Grading System for Post-acne Scarring from English into Brazilian

Received on 04.09.2013.

Approved by the Advisory Board and accepted for publication on 11.10.2013.

* Work performed at the Hospital de Clínicas de Porto Alegre - Universidade Federal do Rio Grande do Sul (HCPA-UFRGS) - Porto Alegre (RS), Brazil. Conflict of interest: None

Financial funding: None

Universidade Federal do Rio Grande do Sul (UFRGS) - Porto Alegre (RS), Brazil.

(C)2014 by Anais Brasileiros de Dermatologia 
Portuguese, adapt it culturally to our population, and verify its reliability and validity. The study followed the steps proposed by the World Health Organization for translations of instruments and was undertaken in agreement with the original authors: ${ }^{10}$

1. Forward translation: a Brazilian dermatologist, whose mother tongue is Portuguese, although also fluent in English, translated the original instrument into Brazilian Portuguese, emphasizing conceptual, rather than literal, translations.

2. Expert panel: A bilingual expert panel composed of 6 professionals analyzed the translated instrument, so that inadequate expressions and concepts could be identified and resolved.

3. Back-translation: In this step, the Portuguese version was translated back into English by an independent translator, whose mother tongue is English and who has no knowledge of the instrument.

4. Approval of the authors: The authors of the original instrument reviewed and approved the back translation.

5. Validation: The final version was consolidated by the panel and considered ready for use. The study population comprised patients with acne scarring at the Dermatology Outpatient Clinic of the Clinics Hospital of Porto Alegre. Before enrollment, each participant or their representative (if aged 18 or under) signed a written consent form in Portuguese. Since the instrument is only used by dermatologists and includes exclusively objective examination parameters, it was not necessary to perform pre-testing and cognitive interviewing. Patients were examined by two independent dermatologists using the translated scale of "Quantitative Global Scarring Grading System for Post-acne Scarring" (Table 1). After 15 days, the instrument was applied once again by one of the dermatologists involved in the first examination. Therefore, the results allowed the analysis of the interobserver variability between the two dermatologists at the first appointment, as well as the intraobserver variability between the same dermatologist at the first and second visits. Since there are no other scales of acne scarring validated in Brazilian Portuguese, it was not possible to conduct a comparison with the translated instrument.

For the validation of the instrument, it was necessary to evaluate 5 patients for each scarring category, in total 30 patients, to detect differences between intraand interobservers' values $(50 \%$ of the standard deviation), given a power of $90 \%$ for an a risk of 0.05 . The mean age of patients was 25.1 years (ranging from 1549 years), and 18 males and 12 females were included.

TABLE 1: Translation into Brazilian Portuguese and validation of the "Quantitative Global Scarring Grading System for Postacne Scarring"

Grau (tipo)

(A) Cicatrizes leves (1 ponto cada)

Macular eritematosa ou pigmentada

Atrófica leve, em forma de prato

(B) Cicatrizes moderadas (2 pontos cada)

Atrófica moderada em forma de prato

Cicatrizes deprimidas com base rasa e pequenas $(<5 \mathrm{~mm})$

Áreas atróficas rasas porém extensas

(C) Cicatrizes graves ( 3 pontos cada)

Deprimidas com base profunda normal e pequenas $(<5 \mathrm{~mm})$

Deprimidas com base profunda anormal e pequenas $(<5 \mathrm{~mm})$

Cicatrizes dérmicas lineares

Áreas atróficas profundas e extensas

(D) Hiperplásicas

Cicatrizes papulares

(D) Hiperplásicas

Quelóide/ cicatriz hipertrófica
Número de lesões: Número de lesões: Número de lesões:

$\begin{array}{lll}1(1-10) & 2(11-20) & 3(>20) \\ 1 \text { ponto } & 2 \text { pontos } & 3 \text { pontos }\end{array}$

2 pontos

4 pontos

6 pontos

3 pontos

6 pontos

9 pontos

2 pontos

4 pontos

6 pontos

Àrea $<5 \mathrm{~cm}^{2}$

Área $5-20 \mathrm{~cm}^{2}$

Área $>20 \mathrm{~cm}^{2}$

6 pontos

12 pontos 

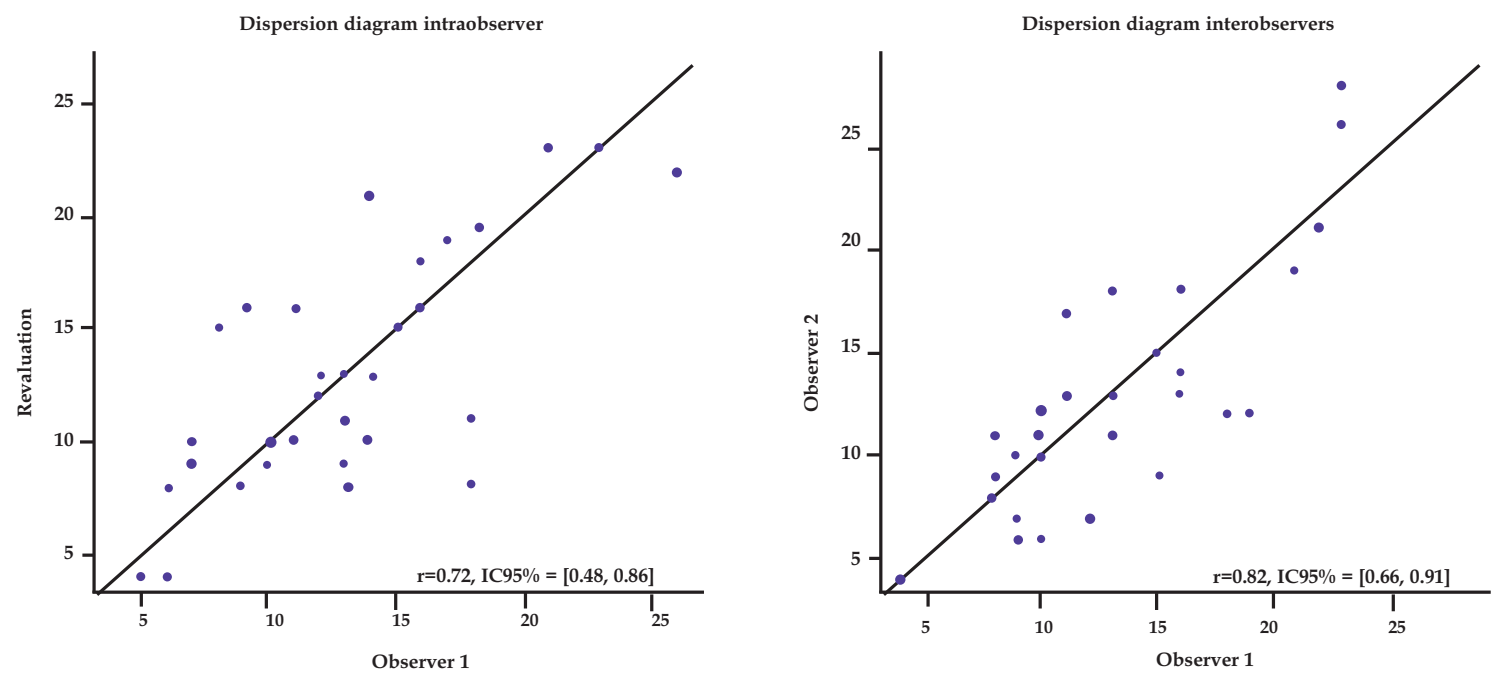

GRAPH 1: Dispersion diagram

The intraclass correlation coefficient (dispersion diagram) was 0.72 for intraobservers and 0.82 for interobservers (as shown in Graph 1). The Student's Ttest did not demonstrate intraobserver or interobserver statistical differences $(p=0.889$ and 0.626 respectively). The Bland and Altman plot was used to evaluate the agreement among the intraobserver and interobserver measurements, showing, respectively, a maximum difference of 7.86 and 6.97 points.

There has been a revolution in the number of techniques that can now be used in the treatment of acne scarring. Therefore, an instrument that grades the severity of scarring eases the choice of treatment and allows comparisons to be made before, after and between treatments. As shown above, our study has demonstrated the consistency and reproducibility of the scale. Hence, the Brazilian Portuguese version of the "Quantitative Global Scarring Grading System for Post-acne Scarring" was validated for our population and can be recommended as a reliable measure to assess acne scarring in Brazilian patients.

\section{REFERENCES}

1. Poli F, Dreno B, Verschoore M. An epidemiological study of acne in female adults: results of a survey conducted in France. J Eur Acad Dermatol Venereol. 2001;15:541-5.

2. Fife D. Practical evaluation and management of atrophic acne scars: tips for the general dermatologist. J Clin Aesthet Dermatol. 2011;4:50-7.

3. Layton AM, Henderson CA, Cunliffe WJ. A clinical evaluation of acne scarring and its incidence. Clin Exp Dermatol. 1994;19:303-8.

4. Dreno B, Katsambas A, Pelfini C, Plantier D, Jancovici E, Ribet V, et al. Combined $0.1 \%$ retinaldehyde/ $6 \%$ glycolic acid cream in prophylaxis and treatment of acne scarring. Dermatology. 2007;214:260-7.

5. Goodman GJ. Postacne scarring: a review of its pathophysiology and treatment. Dermatol Surg. 2000;26:857-71.

6. Tasoula E, Gregoriou S, Chalikias J, Lazarou D, Danopoulou I, Katsambas A, et al. The impact of acne vulgaris on quality of life and psychic health in young adolescents in Greece. Results of a population survey. An Bras Dermatol. 2012;87:862-9.

7. Cotterill JA, Cunliffe WJ. Suicide in dermatological patients. $\mathrm{Br} J$ Dermatol. 1997;137:246-50.

8. Witkowski JA, Parish LC. The assessment of acne: an evaluation of grading and lesion counting in the measurement of acne. Clin Dermatol. 2004;22:394-7.

9. Goodman GJ, Baron JA. Postacne scarring--a quantitative global scarring grading system. J Cosmet Dermatol. 2006;5:48-52.

10. Who.int [Internet]. Process of translation and adaptation of instruments [cited 2013 Aug 18]. Available from: http://www.who.int/substance_abuse/research_tools/translation/en/

MAILING ADDRESS:
Thais Hofmann Cachafeiro
Departamento de Dermatologia
Rua Ramiro Barcelos, 2350
90035-903 - Porto Alegre - RS
Brazil
E-mail: thaishofmann@gmail.com

How to cite this article: Cachafeiro TH, Escobar GF, Maldonado G, Cestari TF. Translation into Brazilian portuguese and validation of the "Quantitative Global Scarring Grading System for Postacne Scarring." An Bras Dermatol. 2014;89(5):851-3. 